\title{
Performance of Steel Pipeline with Concrete Coating (Modeled with Concrete Damage Plasticity) Underseismic Wave Passage
}

\author{
Joanna M. DULINSKA ${ }^{a}$, Dorota JASINSKA ${ }^{b}$ \\ Cracow University of Technology, Warszawska 24, 31-155 Cracow, Poland \\ ajdulinsk@pk.edu.pl, ${ }^{b}$ jasinska@limba.wil.pk.edu.pl
}

\begin{abstract}
Keywords: Concrete damaged plasticity, Pipeline, Concrete coating, Dynamic response, Non-uniformseismic excitation
\end{abstract}

\begin{abstract}
The paper presents the analysis of the dynamic response of a steel pipeline with concrete coating to a real earthquakeregistered in central Poland in 2012. The peak ground acceleration of the shock was scaled up to maximal values predicted for this seismic zone. To represent theinelastic behavior of the material of the concrete coating under dynamic loading, the concrete damaged plasticity constitutive model was assumed. The modelallows to describeplastic strains and irreversible tensile and compression damage that occurs during the cracking process.For seismic analysis two models (uniform and non-uniform)of kinematic excitation were applied. In the modelof uniform excitation it was assumed that the motion of all supports was identical. Inthe model of non-uniform excitation, typical for long structures, the wave passage along the pipelinewith different velocities $(500,400$ and $300 \mathrm{~m} / \mathrm{s})$ was taken into account. It occurred that for the model of uniform excitation the concrete material of the coating remained elastic with no tensile damage. For the model of non-uniform excitation, inelastic behaviour of the coating was observed. The plastic strain areas appeared above all supports. The tensile damage (cracking) wasalso noticed in these areas: the lower wave velocity was assumed, the greater area of concrete coating was affected by plastic strains and tensile damage (cracking). It was the consequence of the quasi-static effects which resulted from ground deformations imposed on the pipeline during the seismic shock.
\end{abstract}

\section{Introduction}

During earthquakes long structures are exposed to spatially different ground vibrations, since their dimensions are comparable with the wave length propagating in the ground. The influence of so called non-uniform seismic excitation on the dynamic response of large-dimensional multiple-support structures was considered by many researchers $[1,2,3]$.The authors mention thatthe wave passage effect may lead to either anincrease or decrease intheglobal dynamic response, depending on therelation between dominant frequencies of excitation and natural frequencies of thestructure [3]. Pipelines, among other multiple-support structures, are especially affected by the non-uniformity of the ground excitation [4]. In rocky terrain, rough terrain configurations such as steep slopes, and for road and river crossings, steel pipelines are covered with concrete coatings. Such coatingsoffer excellent protection of steel pipesfrom both mechanical impact and chemical corrosion.

In this paper the investigation of the performance of a concrete pipeline coating under seismic shock is presented. Different velocities of wave propagation are taken into account.The analysis of the pipeline dynamic response to a small earthquakeis carried out for a $100 \mathrm{~m}$ long section of a steel pipeline with concrete coating. The material of the coating is described with a concrete damage plasticity model $[5,6]$.

\section{The main data of the investigated pipeline}

The investigated 5-span pipeline is laid above the ground andfounded on six concrete supports. The length of each span of the pipeline is $20 \mathrm{~m}$. The outer diameter of the steel pipeis $1.0 \mathrm{~m}$, its thickness is $1.35 \mathrm{~m} \mathrm{1}$ (see Fig. 1). The following properties of steel are considered:elasticity modulus 220GPa and Poisson's ratio 0.3. The thickness of the concrete coating is $0.2 \mathrm{~m}$. 
A 3D finite element model of the structure (see Fig. 1) was developed using the ABAQUS software [7].The steel pipe was discretized by continuum 8-node shell elements, whereas the concretecoating was discretized by 3D linear brick8-node finite elements. The local mesh densification was implemented in supports' zones, where concentration of stresses was predicted. The total number of degrees of freedom was about 450000 .

(a)

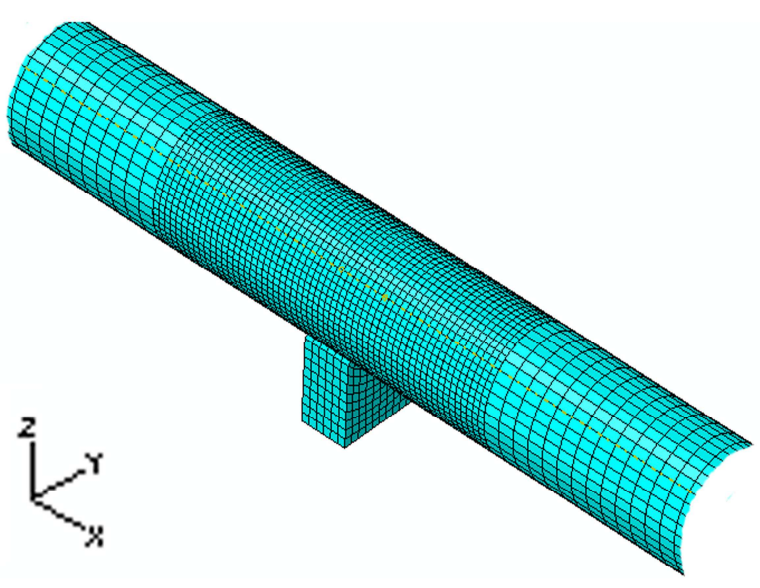

(b)

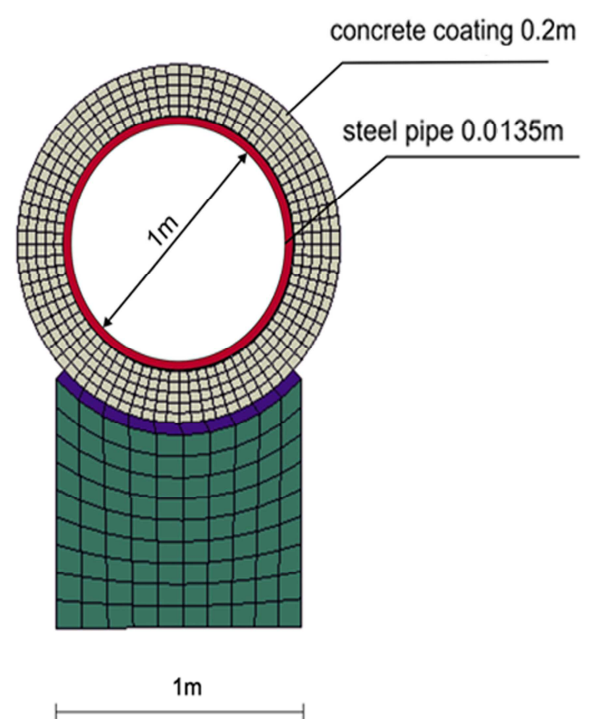

Fig. 1 (a) Fragment of 3D numerical modelof the pipelinewith local mesh densification, (b)cross-section of the pipeline

For the dynamic analysis the Rayleigh model of mass and stiffness proportional damping was applied. The damping coefficients $\alpha$ and $\beta$ were determined for damping ratios $\xi_{1}, \xi_{2}(5 \%)$ referring to frequencies $f_{1}$ and $f_{2}$,respectively. As the first natural frequency of the pipeline $f_{1}=7.39 \mathrm{~Hz}$ in the $x-z$ plane (see Fig. 1a)was assumed. As the second frequency $f_{2}=8.31$ Hzin the $x-z$ plane was used.

\section{Constitutive parameters for concrete damaged plasticity model}

To represent the inelastic behavior of the concrete coating of the steel pipeline a continuum, plasticity-based, damage model called concrete damaged plasticity (CDP) was assumed as a constitutive model for the concrete [5,6]. The model, provided by the ABAQUS software, is designed for applications in which concrete is subjected to cyclic, dynamic loading like during an earthquake.The model combines non-associated multi-hardening plasticity and scalar damaged elasticity to describe the irreversible damage that occurs during the fracturing process. The yield surface is controlled by two hardening variables representing equivalent plastic strains: $\widetilde{\mathcal{\varepsilon}}_{t}^{p l}$ and $\widetilde{\mathcal{\varepsilon}}_{c}^{p l}$, referring to failure mechanisms under tension and compression loading, respectively. The damage of concrete is characterized by two damage variables: $d_{t}$ (tension) and $d_{c}$ (compression), which are functions of the plastic strains. The CDP model assumes that the reduction of the elastic modulus is given in terms of a scalar degradation variable SDEG as: $E=(1-S D E G) E_{0}$, where $E_{0}$ is the initial (undamaged) modulus of the material.

The main parameters of the concrete material were as follows: elasticity modulus $19.7 \mathrm{GPa}$, Poisson's ratio 0.19 , and dilation angle $38^{\circ}$. The essential constitutive parameters of the model were assumed according to laboratory tests[8], which are summarized in Table 1.

The concrete material ofthe supports was assumed to behomogeneous and linear-elastic. The modulus of elasticity was taken as $40 \mathrm{GPa}$. ThePoisson's ratio was assumed as 0.2. 
Table 1 Constitutive parameters of the concrete damaged plasticity model [8]

\begin{tabular}{|l|l|l|l|l|l|l|l|}
\hline \multicolumn{2}{|c|}{ Concrete tensionstiffening } & \multicolumn{2}{c|}{$\begin{array}{c}\text { Concrete tension } \\
\text { damage }\end{array}$} & \multicolumn{2}{c|}{$\begin{array}{c}\text { Concrete compression } \\
\text { hardening }\end{array}$} & \multicolumn{2}{c|}{$\begin{array}{c}\text { Concrete compression } \\
\text { damage }\end{array}$} \\
\hline $\begin{array}{c}\text { Stress } \\
{[\mathrm{MPa}]}\end{array}$ & $\begin{array}{c}\text { Cracking strain } \\
{[-]}\end{array}$ & \multicolumn{1}{|c|}{$d_{t}[-]$} & $\begin{array}{c}\text { Cracking strain } \\
{[-]}\end{array}$ & $\begin{array}{c}\text { Stress } \\
{[\mathrm{MPa}]}\end{array}$ & $\begin{array}{l}\text { Crushing strain } \\
{[-]}\end{array}$ & $d_{c}[-]$ & $\begin{array}{c}\text { Crushing strain } \\
{[-]}\end{array}$ \\
\hline 1.99893 & 0.0 & 0.0 & 0.0 & 15.0 & 0.0 & 0.0 & 0.0 \\
\hline 2.842 & 0.00003333 & 0.0 & 0.00003333 & 20.197804 & 0.0000747307 & 0.0 & 0.0000747307 \\
\hline 1.86981 & 0.000160427 & 0.406411 & 0.000160427 & 30.000609 & 0.0000988479 & 0.0 & 0.0000988479 \\
\hline 0.862723 & 0.000279763 & 0.69638 & 0.000279763 & 40.303781 & 0.000154123 & 0.0 & 0.000154123 \\
\hline 0.226254 & 0.000684593 & 0.920389 & 0.000684593 & 50.007692 & 0.000761538 & 0.0 & 0.000761538 \\
\hline 0.056576 & 0.00108673 & 0.980093 & 0.00108673 & 40.236090 & 0.002557559 & 0.195402 & 0.002557559 \\
\hline
\end{tabular}

\section{Seismic input data}

In this study a real seismic shock of magnitude 3.8 in Richter scale that occurred in January 2012 in Poland was used as thekinematic excitation of the pipeline. The peak ground accelerations in WE direction reached a value of $0.0015 \mathrm{~m} / \mathrm{s}^{2}, 0.001 \mathrm{~m} / \mathrm{s}^{2}$ in NS direction and $0.0006 \mathrm{~m} / \mathrm{s}^{2}$ in vertical direction. The time histories of acceleration in these directions applied for dynamic analysis as kinematic excitations of the pipeline are shown in Fig. 2. (direction WE refers to $x$ direction, parallel to the pipeline; direction NS refers to $y$ direction, perpendicular to the pipeline).

For the purpose of this study the registered data wasscaled up, so the peak ground acceleration raised to $0.6 \mathrm{~m} / \mathrm{s}^{2}$ in WE direction, $0.4 \mathrm{~m} / \mathrm{s}^{2}$ in NS direction and $0.2 \mathrm{~m} / \mathrm{s}^{2}$ in vertical direction $\mathrm{Z}$. It means that the investigated pipeline is situated in the zone with maximal horizontal peak ground acceleration of the shock equal to $0.72 \mathrm{~m} / \mathrm{s}^{2}$. This value corresponds to PGA of earthquakes predicted in seismic hazard studies for central and southern Poland [9]. The scaled records were also filtered to a maximum frequency of $10 \mathrm{~Hz}$.The signal analysis showed that the dominant frequencies of the earthquake ground motions in theWE direction are located in the range from 3.5 to $4.1 \mathrm{~Hz}$. Similar dominant ranges of frequencies were also obtained for theNS and Z directions. Hence, it could be concluded that the natural frequencies of the pipeline and the dominant frequencies of the shock differ significantly, hence there is no danger of the resonance phenomenon.
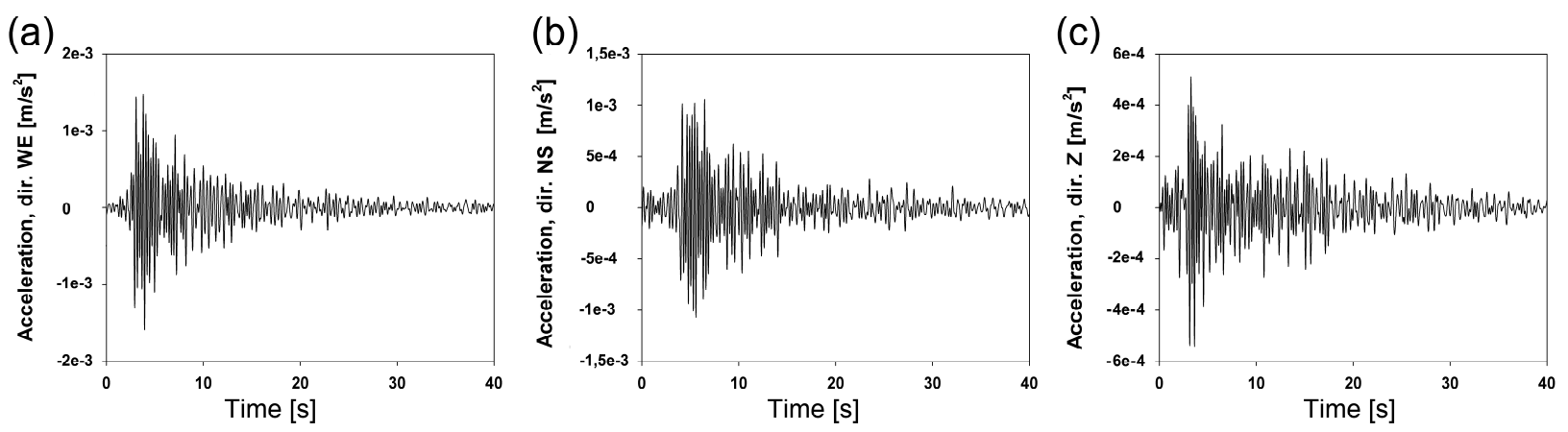

Fig. 2 Time histories of ground accelerations: (a) horizontal direction $\mathrm{x}$, parallel to the pipeline, (b) horizontal direction $\mathrm{y}$, perpendicular to the pipeline, (c) vertical direction $\mathrm{z}$

\section{Dynamic response of the pipeline to seismic shock}

A model of non-uniform kinematic excitation,taking into account thewave passage effect, was applied for the dynamic calculations. It assumed that subsequent points of the ground in the direction of wave propagation repeat the same movement with a certain time delay dependent on the wave velocity. Wave velocities 300, 400 and $500 \mathrm{~m} / \mathrm{s}$ were considered. For comparison a model of uniform 
kinematic excitation, corresponding to the assumption of the infinite velocity of wave propagation in the ground, was taken into account.

The time history analysis wascarried out with the Hilber-Hughes-Taylor time integration algorithm provided in the ABAQUS software for a direct step-by-step solution. As the concrete damage plasticity model implements strong nonlinearity, a step of integration was not fixed. It varied from $10^{-5}$ to $10^{-2} \mathrm{~s}$, according to convergence requirements. A small value ofartificial damping $(0.05)$ was also introduced into the system to ensure numerical stability.

Firstly, the model of uniform seismic excitation was assumed. It occurred that neither tensile damage nor stiffness degradation occurred. Only tiny zones of small plastic strains of about $10^{-6}$ concentrated above supports were observed. Then, consecutively, decreasing wave velocities from 500 to $300 \mathrm{~m} / \mathrm{s}$ were adopted in the model of non-uniform kinematic excitation.

Fig. 3 presents the vertical deformation of the pipeline for the non-uniform kinematic excitation (wave velocity $\mathrm{v}=300 \mathrm{~m} / \mathrm{s}$ ) as well as for the uniform excitation $(\mathrm{v}=\infty)$. The comparative analysis shows the difference in dynamic behaviour of the pipeline in both cases. When the wave passage effect is taken into consideration (see Fig. 3a), the deformation of the pipeline resulting from geometrical changes of the ground is clearly visible. In case of uniform kinematic excitation (see Fig. $3 b)$ the deformation of the pipeline results from inertia forces only.

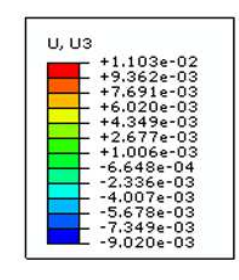

(a) NON-UNIFORM EXCITATION (WAVE PASSAGE VELOCITY $300 \mathrm{M} / \mathrm{S}$ )

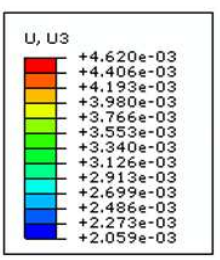

(b) UNIFORM EXCITATION

Fig. 3 Vertical deformation of the pipeline (overscaled): (a) for non-uniform kinematic excitation (wave velocity $\mathrm{v}=300 \mathrm{~m} / \mathrm{s})(\mathrm{b})$ for uniform excitation $(\mathrm{v}=\infty)$

Fig. 4 shows the inelastic behaviour of the concrete coating in case of non-uniform kinematic excitation with wave velocity assumed as $500 \mathrm{~m} / \mathrm{s}$. It occurred that the concretecoatingremained elastic except from all supports' zones (see Fig. 4a), where some plastic strains appeared, close to the outer surface of the coating (see Fig. 4b). For this wave velocity neither tensile nor compression damage took place. The stiffness of the concrete coating remained undegraded.

(a)

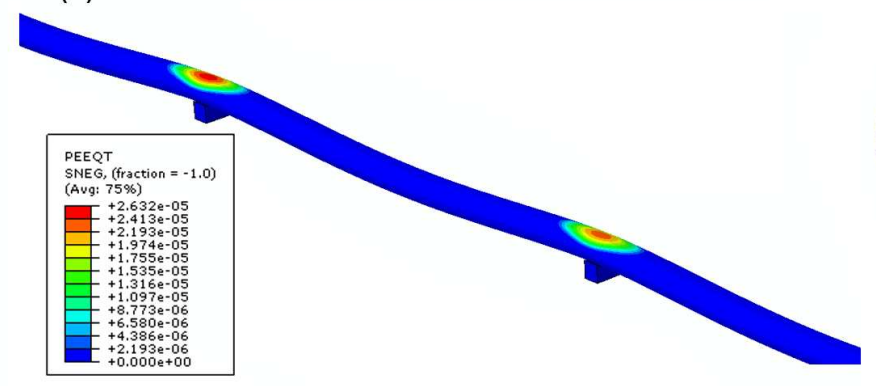

(b)

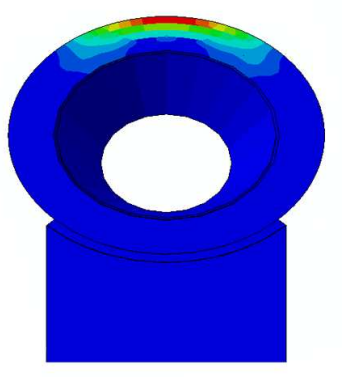

Fig. 4 Distribution of plastic strains in concrete coating (wave velocity $500 \mathrm{~m} / \mathrm{s}$ ):

(a) location of plastic strains above supports(b) cross section above the central support

Figs 5 and 6 illustrate the inelastic behaviour of the concrete coating for wave velocity $400 \mathrm{~m} / \mathrm{s}$. In this case, in addition to plastic strains occurring in all supports' zones, tensile damage took place above one support (see Fig. 5a).The comparison of Figs5b and 5c indicates that the values of plastic 
strainsabove the support where the tensile damage appeared were about 100 times greater than values of plastic strains above other supports. Fig. 6a shows the pattern of the tensile damage of the concrete coating whereas Fig. $6 \mathrm{~b}$ depicts the distribution of the tensile damage along the cross section of the coating.

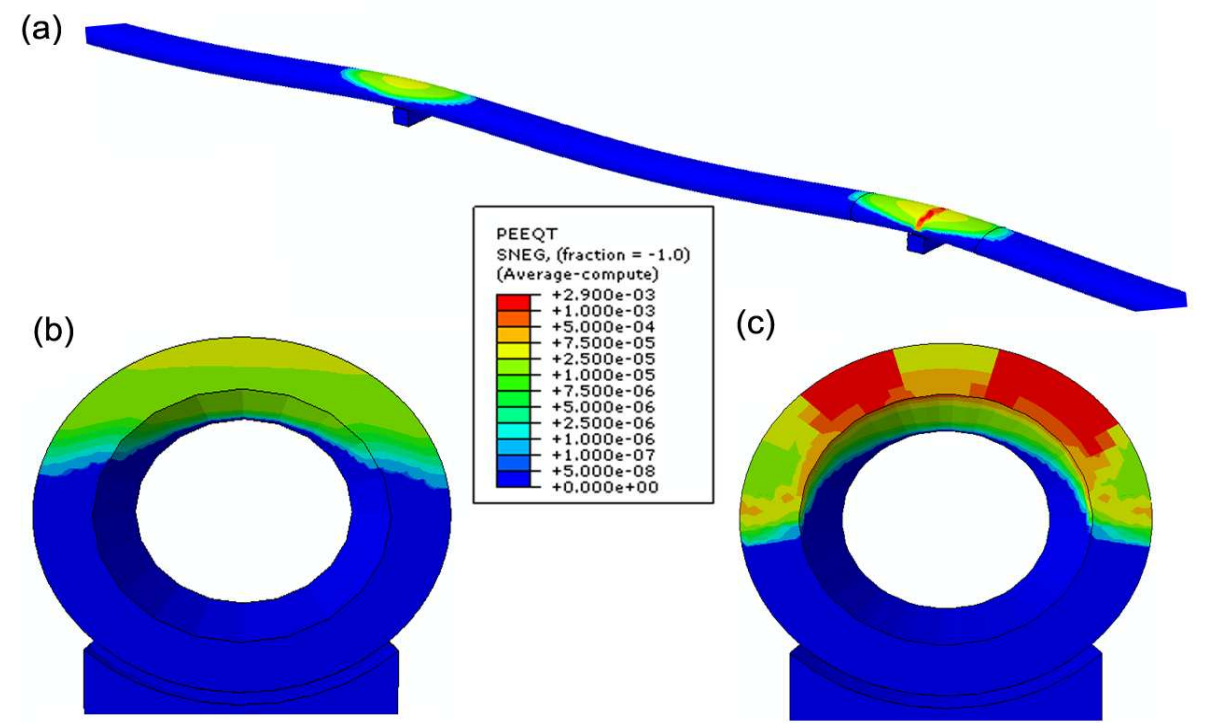

Fig. 5 Inelastic behaviour of concrete coating (wave velocity $400 \mathrm{~m} / \mathrm{s}$ ): (a) location of plastic strains and tensile damage (above right support) (b) distribution of plastic strains (cross section above left support), (c) distribution of plastic strains (cross section above right support)

(a)

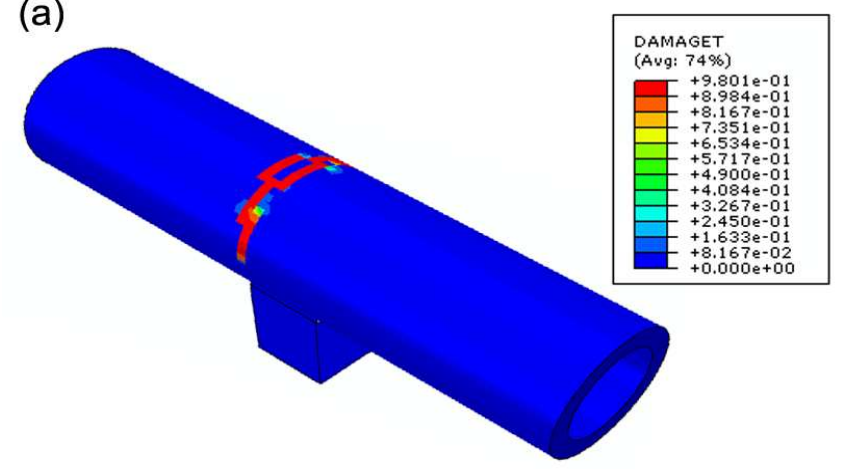

(b)

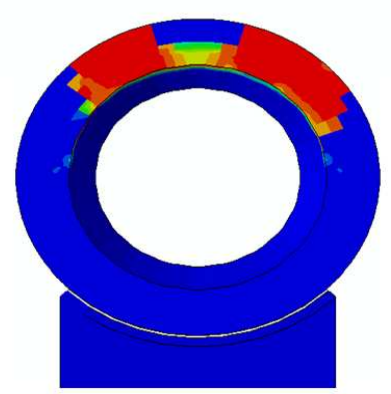

Fig. 6 (a) Pattern of tensile damage of the concrete coating (wave velocity $400 \mathrm{~m} / \mathrm{s}$ ), (b) distribution of tensile damage (cross section above support)

Finally, wave velocity of $300 \mathrm{~m} / \mathrm{s}$ was implemented. The detailed analysis proved that the lowest velocity resulted in crackingof the concrete coating above all pipeline supports. In addition(see Fig.7) plastic strains appeared in the bottom part of the middle area of each span.

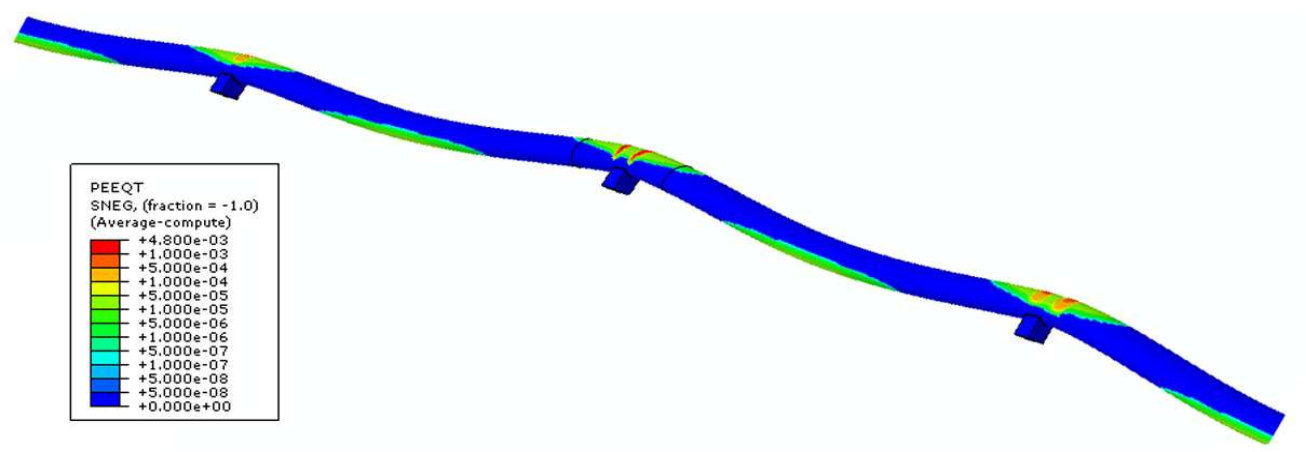

Fig. 7 Location of tensile damage above all supports and plastic strains in the middle area of each span (wave velocity $300 \mathrm{~m} / \mathrm{s}$ ) 
It has to be pointed out that during the investigated earthquake, which was relatively small, the steel material remained linear-elastic. The maximum Misses' stresses, which were generated by the shock, reached $50 \mathrm{MPa}$.

\section{Conclusions}

In the paper the results of calculations of the dynamic response of the steel pipeline with concrete coating under the real seismic shock were presented. The effect of wave passage along the pipeline was taken into consideration. To represent inelastic behaviour of the coating the concrete damaged plasticity model was assumed. In summary, the following final conclusions can be formulated:

- For the model of uniform seismic excitation the concrete material of the coating remained elastic with no tensile damage (cracking),

- For the model of non-uniform seismic excitation, which takes theso called wave passage effect into account, inelastic behaviour of the concrete coating could be observed. The plastic strain areas appeared above all supports. Tensile damage (cracking) could also be noticed in these areas: the lower wave velocity was assumed, the greater area of concrete coating was affected by plastic strains and tensile damage (cracking). It was the consequence of the quasi-static effects which resulted from changes of the geometry of the subsoil during the seismic shock.

- No damages were observed in the steel pipe, regardless of the model of seismic excitation or assumed wave velocity.

The comparative analysis of the results revealed thatthe consideration of the wave passage effectled to greaternon-linear dynamic response (plastic strains and tensile damage) of the concrete coating described with the concrete damaged plasticity model than the assumption of uniform seismic excitation. Hence, in this case imposed seismic ground deformation sratherth aninertial forces dominate the structure' sseismic response. However, it should be emphasized that the results might be opposite if the range of the dominant frequencies of the shock contained the natural frequencies of the pipeline and the resonance phenomenon could take place.

\section{References}

[1] A. Zerva, Spatial variation of seismic ground motion. Modeling and engineering applications, CRC Press, Taylor \& Francis Group, Boca Raton, FL, 2009

[2] J. M. Dulinska, Cooling tower shell under asynchronous kinematic excitation using concrete damaged plasticity model, Key Engineering Materials, 535-536 (2013) 469-472.

[3] J.M. Dulinska, Influence of wave velocity in the ground on dynamic response of large dimensional structures, Int. Journal of Earth Sciences and Engineering, 4 (2011) 538-541.

[4] Y. Yong, Response of pipeline structure subjected to ground motion excitation, Engineering Structures, 19 (1997) 679-684.

[5] J. Lubliner, J. Oliver, S. Oller, E. Oñate, A Plastic-Damage Model for Concrete, International Journal of Solids and Structures, 25 (1989) 229-326.

[6] J. Lee, G. L. Fenves, Plastic-Damage Model for Cyclic Loading of Concrete Structures, Journal of Engineering Mechanics, 124 (1998) 892-900.

[7] ABAQUS, Users Manual V. 6.12-2, Dassault Systemes Simulia Corp., Providence, RI (2012).

[8] T. Jankowiak, T. Lodygowski, Identification of parameters of concrete damage plasticity constitutive model, Foundations of Civil and Environmental Engineering, 6 (2005) 53 - 69.

[9] V. Schenk, Z. Schenková Z., P. Kottnauer, B. Guterch, P. Labák P., Earthquake hazards maps for the Czech Republic, Poland and Slovakia, Acta Geoph. Pol., 49(2001) 287-302. 